\title{
Investigation and Optimization of a Cooling System Prototype for a Module of the Silicon Tracking System for the BM@N Experiment
}

\author{
D. V. Dementev ${ }^{a}$, T. Z. Lygdenova ${ }^{a, b}$, and P. I. Kharlamov ${ }^{a, c, *}$ \\ ${ }^{a}$ Joint Institute for Nuclear Research, Veksler and Baldin Laboratory of High Energy Physics, \\ Dubna, Moscow oblast, 141980 Russia \\ ${ }^{b}$ National Research Tomsk State University, \\ Tomsk, 634050 Russia \\ c Skobel'tsyn Institute of Nuclear Physics, Moscow State University, \\ Moscow, 119991 Russia \\ *e-mail: pi.kharlamov@physics.msu.ru
}

Received May 25, 2020; revised June 26, 2020; accepted June 27, 2020

\begin{abstract}
Various materials were tested for use in the elements of the cooling system for the readout electronics of the BM@N silicon tracking detector. The thermal design was performed using the ANSYS software package and the thermal conductivities of various adhesives and carbon-fiber composites were experimentally measured. The results were used to select materials for cooling fins. Thermal tests of the prototypes of front-end-board boxes have been carried out, during which various thermal interfaces were also tested.
\end{abstract}

DOI: $10.1134 / \mathrm{S} 0020441220060159$

\section{INTRODUCTION}

The Barionic Matter at Nuclotron (BM@N) experiment [1] is performed on extracted beams of the NICA Nuclotron accelerating facility in Dubna to study nuclear matter in collisions of relativistic heavyion beams (with $Z$ as high as $Z$ of gold) with energies of up to $4.5 \mathrm{GeV} /$ nucleon with a fixed target. BM@N is the first experiment that is carried out at the NICA Nuclotron accelerating facility. The silicon tracking system is a key part of the BM@N tracking system. The silicon tracking system is based on tracking modules that include readout electronics and double-sided microstrip silicon sensors.

The BM@N silicon tracking system is expected to have more than 600000 channels and operate at a high detector occupancy. The system largely duplicates the general engineering solutions of the projected tracking system of the CBM experiment at the FAIR accelerator facility [2], which is under construction in Darmstadt, Germany, but is not identical to it; in particular, its cooling system differs significantly.

As is the case of the CBM experiment, fast multichannel electronics are used in the silicon tracking system to process the detector signals. The generation of a large amount of heat is a side effect of such electronics. This heat must be removed from the thermostat in which the detector is housed. High-efficiency heat removal requires the use of the most efficient thermal interfaces between chips and cooling fins, as well as between heat sinks and the cooling plate.

\section{THE EXPERIMENTAL TECHNIQUE}

\subsection{The Thermal-Interface Concept}

The silicon tracking system, whose general design was described in [3], consists of four stations. The stations include double-sided microstrip sensors, which are connected to the front-end boards (FEBs) by ultra-light multilayer aluminum-polyimide cables. This forms the so-called modules that are fixed in place on carbon-fiber support structures.

Eight dedicated STS-XYTER application-specific integrated circuits, each of which dissipates a thermal power of approximately $1.2 \mathrm{~W}$, are the main heat sources on an FEB. Since the readout chip must process small-amplitude analog signals and must provide an extremely low noise level, the FEB itself contains four low-dropout (LDO) voltage regulators with a power dissipation of $\sim 0.8 \mathrm{~W}$ each. The total power dissipation is as high as $13 \mathrm{~W}$ per FEB.

The main difficulty that was encountered during the development is the limited space inside an analyzing magnet, where all the sensors and all the readout electronics must be located. In this regard, it was necessary to design the heat sink in view of the available volume and to minimize the use of heavy materials. In 


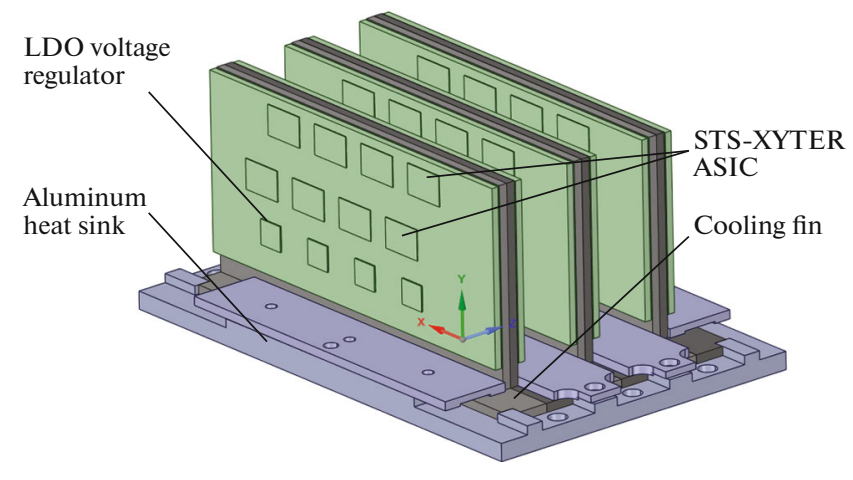

Fig. 1. The diagram of the thermal interface.

addition, magnetic materials had to be completely excluded.

In this paper, we describe the study of the thermal interfaces of the FEBs. The diagram of the thermal interface is shown in Fig. 1. The FEBs are attached to cooling fins through a thin layer of heat-conducting material. The cooling fins are mounted on a platform (an aluminum heat sink), which is fixed in place on a water-cooled plate. This design can be attributed to the technology for assembling the detector, which was described in detail in [3].

A prototype in which a miniature heating element made from a nichrome wire was used as a simulator of a 300- $\mu \mathrm{m}$-thick STS-XYTER application specific integrated circuit was created to study the methods for efficient heat removal. Since chips are the main sources of heat on an FEB, the heat losses on conducting paths on the FEB and in its connectors were ignored in the thermal design.

\subsection{Selection of the Material for the Cooling Fins}

Aluminum and copper are most commonly used in cooling systems owing to their high thermal conductivity $[4,5]$. Although copper has the highest thermal conductivity, it is inapplicable in the BM@N experiment, since copper is strongly activated under high radiation background conditions [6]. Many aluminum alloys with different thermal conductivities that depends on the purity of the alloy exist; however, alloys with the highest thermal conductivity are difficult to process mechanically [7].

Novel heat-conducting composite materials are being developed as an alternative to aluminum [8]. The thermal conductivity of a carbon composite material made from KT13D1U/EX1515 prepreg manufactured by TenCate Advanced Composites (United States) was measured in [9]. This material has a high thermal conductivity of $269 \mathrm{~W} /(\mathrm{m} \cdot \mathrm{K})$ in the direction along the fiber and a substantially lower thermal conductivity of $15 \mathrm{~W} /(\mathrm{m} \cdot \mathrm{K})$ in the direction perpendicular to the fiber.
Two carbon composite samples with the same composition, but with different thicknesses were also compared in [9]. The thermal conductivity along the fiber was 269 and $233 \mathrm{~W} /(\mathrm{m} \cdot \mathrm{K})$ for samples with thicknesses of 78 and $156 \mu \mathrm{m}$, respectively. From these data, it follows that the amount of binder in the composition of a carbon-composite sample increases with an increase in the sample thickness, which worsens the thermal characteristics of the sample.

In our case, high thermal conductivity is the most important criterion for the quality of the adhesive joint. It is also necessary that the thermal interface between the FEB and the fin be an electrical insulator capable of withstanding a breakdown voltage of $500 \mathrm{~V}$ or greater. Searching for an adhesive with the highest thermal conductivity was one of the tasks of this study.

The influence of the porosity of polymeric materials on their thermal conductivity was investigated and the decrease in the coefficient of thermal conductivity of a material in the presence of gas pores in it was established. Thus, the coefficient of thermal conductivity decreased by $26 \%$ when the relative porosity in glass fiber laminate increased from 0.1 to 0.3 [10]. The decrease in the thermal conductivity of this material is explained by the presence of gas inclusions filled with adhesive-joint decomposition products, whose thermal conductivity does not exceed $5-10 \%$ of the thermal conductivity of the binding compound [11]. It is possible to increase the thermal conductivity of the adhesive by $0.6-0.7 \mathrm{~W} /(\mathrm{m} \cdot \mathrm{K})$ by increasing the packing density of particles in adhesives using fillers [12].

In this study, we examined several materials that are suitable for making a cooling fin: aluminum and various composite materials based on carbon-fiber prepregs [9]. A test facility (Fig. 2) was prepared for measuring the thermal conductivity of samples.

The thermal conductivity of the materials was calculated in accordance with the Fourier law from the values of heat fluxes and temperature drops, which obey the linear dependence on the distance to the cooler on both aluminum fins (Fig. 2). The average value of heat transfer was calculated according to the formula:

$$
Q=\frac{Q_{1}+Q_{2}}{2}=\lambda_{\mathrm{Al}} A \frac{d T_{1} / d x_{1}+d T_{2} / d x_{2}}{2},
$$

where $Q_{1}$ and $Q_{2}$ are the heat flows through the cooling fin between the cooler and the heater, respectively; $A$ is the heat-exchange surface area; and $d T / d x$ is the slope of the graph of the temperature dependence on the distance between the cooler and the thermocouples that measure the temperature of the fins. An illustration is the graph shown in Fig. 3, where curve 1 corresponds to the fin with the cooler and curve 2 corresponds to the fin with the heater. 


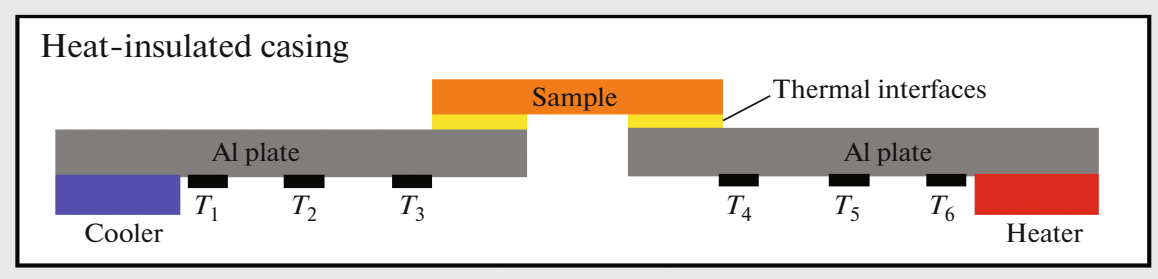

Fig. 2. The test facility for measuring the thermal conductivity in the plane direction: $\left(T_{1}-T_{6}\right)$ thermocouples.

\section{THE MEASUREMENT RESULTS}

\subsection{The Materials of the Fins}

The test facility for studying the thermal conductivity of materials (Fig. 2) consists of two duralumin plates (D16T grade) with a thickness of $0.72 \mathrm{~mm}$, a width of $50 \mathrm{~mm}$, and a length of $100 \mathrm{~mm}$.

The plates are placed apart at a fixed distance. One plate is connected to a heater and the other is connected to an aluminum heat sink that is connected to a cooling thermostat (LAUDA MC 250), which maintains a fixed temperature at the end of the plate with an accuracy of $\pm 0.5^{\circ} \mathrm{C}$. Three thermocouples were fixed in place on each aluminum plate (cooling fin), so that their position on the fins was precisely defined.

To prevent heat losses by radiation and convection, the entire structure was placed in a heat-insulated casing made of Airex C70.75 foam with a thermal conductivity of $0.033 \mathrm{~W} /(\mathrm{m} \cdot \mathrm{K})$.

As described above, the thermal resistance was calculated based on the measurement of the heat flow $Q$ and the temperature gradient $\Delta T$, which was calculated using the graphs shown in Fig. 3.

The difference between the thermal flows $Q_{1}$ and $Q_{2}$ can be attributed to the heat losses by thermal radiation of the sample. An aluminum-foil shield was placed a few millimeters above the sample to minimize the influence of this effect on the measurements.

To check the reliability of the experiment, a duralumin sample was taken from the same material as the material of the cooling fins, and a thermal model was built using the ANSYS software system. The calculated temperatures coincided with the experimental values within the measurement accuracy, which made it possible to judge the correctness of the measurements and confirmed that thermal losses for heating the environment under the experimental conditions can be neglected.

Several possible materials for manufacturing the fins were tested in our study. Apart from the duralumin, various carbon composite materials made from carbon-fiber prepregs with a high thermal conductivity were examined.

Carbon-fiber reinforced plastic samples $50 \mathrm{~mm}$ wide and $20 \mathrm{~mm}$ long were fixed in place on both alu- minum plates with a joint area of $2.5 \times 50 \mathrm{~mm}^{2}$ each. When calculating the thermal resistance, it is also necessary to take the resistances of the thermal interface between the sample and the fins into account. The total thermal resistance in our case consists of several series resistances of the sample, the fins, and the thermal interfaces between them. A $800-\mu$ m-thick doublesided tape with a measured thermal resistance of $9.2 \pm$ $1.9 \mathrm{~K} / \mathrm{W}$ that was taken into account in the calculation was used as an interface between the aluminum plates and the sample.

We measured the parameters of five samples with different thicknesses, with different numbers and orientations of prepreg layers, and with fillers (FGS-003 graphene paper and diamond powder):

- sample 1: three K13D2U prepreg layers $0.75-\mathrm{mm}$ thick;

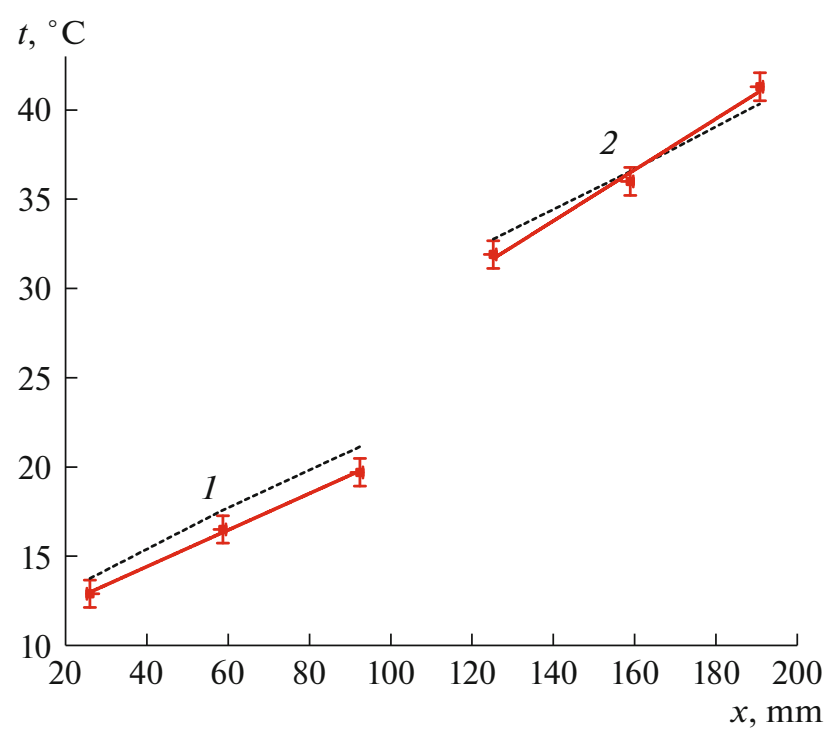

Fig. 3. The graph for determining the temperature gradient: (1) the fin with the cooler and (2) the fin with the heater. The test sample was carbon-fiber reinforced plastic with the addition of diamond powder, which was attached to an adhesive tape. The solid line presents the experimental values and the dashed line presents the results of the calculation using the ANSYS software system. 
Table 1. The thermal conductivity of different types of carbon-fiber reinforced plastic in directions parallel and perpendicular to a fiber

\begin{tabular}{|c|c|c|}
\hline \multirow[b]{2}{*}{ Sample } & \multicolumn{2}{|c|}{ Thermal conductivity, $\mathrm{W} /(\mathrm{m} \cdot \mathrm{K})$} \\
\hline & along the fiber & $\begin{array}{l}\text { perpendicularly } \\
\text { to the fiber }\end{array}$ \\
\hline No. 1 (3 layers of prepreg with a total thickness of $0.75 \mathrm{~mm}$ ) & $12 \pm 4.7$ & $3.7 \pm 0.9$ \\
\hline No. 2 (6 layers of prepreg $1.27 \mathrm{~mm}$ thick) & $17 \pm 4.5$ & $8 \pm 2$ \\
\hline $\begin{array}{l}\text { No. } 3 \text { (6 layers of prepreg with FGS graphene paper }(0.03 \mathrm{~mm}) \text { at the edges with a total } \\
\text { thickness of } 1 \mathrm{~mm})\end{array}$ & $64 \pm 12.1$ & $22 \pm 3.7$ \\
\hline $\begin{array}{l}\text { No. } 4 \text { (prepreg with FGS graphene paper }(0.03 \mathrm{~mm}) \text { and with the addition of diamond } \\
\text { powder with a total thickness of } 0.7 \mathrm{~mm})\end{array}$ & $254 \pm 82.9$ & $14 \pm 3.4$ \\
\hline $\begin{array}{l}\text { No. } 5 \text { (4 layers of prepreg, layers of carbon fabric }(5 \mathrm{~mm}) \text { along the edges on both sides, } \\
\text { and } 10 \text { layers of FGS graphene paper and epoxy resin at the center) }\end{array}$ & $147 \pm 28.1$ & - \\
\hline
\end{tabular}
thick;

- sample 2: six K13D2U prepreg layers 1.27-mm

- sample 3: six K13D2U prepreg layers with FGS003 graphene paper along the edges with a total thickness of $1 \mathrm{~mm}$;

- sample 4: K13D2U prepreg with FGS-003 graphene paper and the addition of two diamondpowder fractions $(30-40$ and $7-10 \mu \mathrm{m})$ with a total thickness of $0.7 \mathrm{~mm}$;

- sample 5: four prepreg layers, with T300 carbonfabric layers with a surface density of $2 \mathrm{~g} / \mathrm{m}^{2}$ along the edges $(5 \mathrm{~mm})$ on both sides, and with ten layers of FGS-003 graphene paper and ED20 epoxy adhesive with Etal-45M hardener at the center.

FGS-003 graphene paper from AMEC Thermasol has a thickness of $30 \mu \mathrm{m}$; its thermal conductivity is $1500 \mathrm{~W} /(\mathrm{m} \cdot \mathrm{K})$ along a fiber and $15 \mathrm{~W} /(\mathrm{m} \cdot \mathrm{K})$ perpendicular to the fiber. The thermal conductivity values obtained for these samples are presented in Table 1. The measurements were made in directions along the fiber $\left(0^{\circ}\right)$ and across it $\left(90^{\circ}\right)$.

The temperature dependences were plotted to calculate the thermal conductivity of the fin materials (similarly to Fig. 3). The values calculated using the ANSYS software system differ from the results of measurements by an average of $2^{\circ} \mathrm{C}$, which can be attributed to the error $\lambda$ that was calculated above.

\subsection{An Adhesive between an FEB and a Fin: Comparison of Adhesives with Diamond Powder}

The measurement of the transverse thermal conductivity of thin materials is based on principles that are similar to those described in Subsection 1.2. Two aluminum blocks (Fig. 4) had dimensions of $50 \times 20 \times$ $20 \mathrm{~mm}$ [13]. The upper aluminum block was glued to the heater. The lower block was cooled using a thermostat. The temperature at fixed points $\left(T_{1}-T_{6}\right)$ was measured by thermocouples.

Production of multicomponent adhesive requires that the nonuniform distribution of components with different masses, as well as the possibility of air bubbles being formed inside the volume be taken into account. All these factors affect the thermal conductivity of the samples. Therefore, a specialized centrifugal mixer (THINKY ARE-250) was used to knead the adhesives.

Seven samples were tested. Six $100-\mu$ m-thick samples were produced from a mixture of epoxy adhesive with different diamond-powder fractions, and one sample was a mixture with boron nitride:

- no. 1: two fractions of diamond powder in a mass ratio with the adhesive of $1: 1: 1$;

- no. 2: a fine fraction of diamond powder in a mass ratio with the adhesive of $1: 1$;

- no. 3: coarse fraction of diamond powder in a mass ratio with the adhesive of $1: 1$;

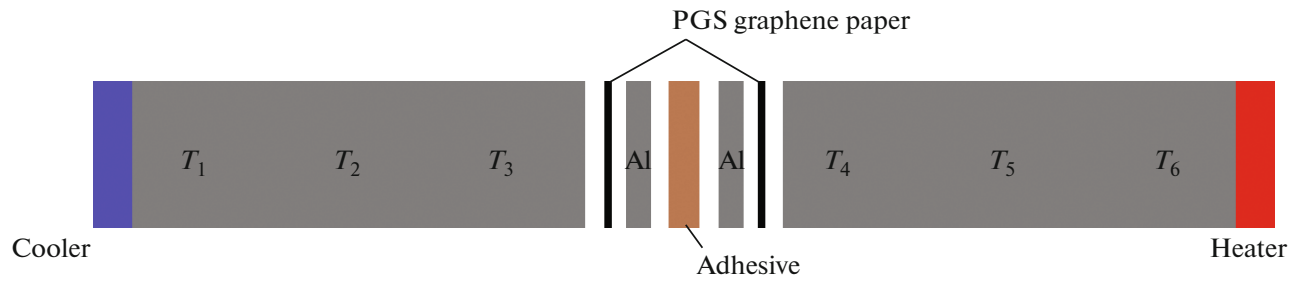

Fig. 4. The test facility for measuring the thermal conductivity in a thin layer. 
- no. 4: two fractions of diamond powder in a mass ratio with the adhesive of $1: 1: 2$;

- no. 5: two fractions of diamond powder in a mass ratio of the coarse fraction with the fine fraction with the adhesive of $4: 1: 5$;

- no. 6: two fractions of diamond powder in a mass ratio of the coarse fraction with the fine fraction with the adhesive of $90: 5: 57$;

- no. 7: boron nitride with KTK silver-containing conductive adhesive in a mass ratio of $1: 10$.

The main task of the testing was to measure the thermal resistance of an adhesive layer with a fixed thickness. According to the measurement results, sample 6 with the addition of two fractions of diamond powder with a ratio of fine to coarse fractions of $1: 18$ showed the lowest thermal resistance. It can be assumed that the fine fraction filled the space among the coarse fractions, thus increasing the total thermal conductivity of the layer.

The nonsphericity of diamonds presumably will not strongly affect the packing density, since the random packing densities for Platonic solids and for spheres differ only slightly [14]. This allows one to estimate the density of random packing of two-fraction diamond powder [15] (with the scatter of the diamond-powder sizes being ignored).

In our case, the packing density is estimated as $76 \%$, which could lead to a mass ratio of the coarse fraction of diamonds to their fine fraction and to the adhesive as $14: 5: 2$. Nevertheless, experience has shown that a composition with a small amount of glue loses its adhesive properties. For this reason, a composition with a smaller amount of the fine fraction and a large amount of the adhesive was used in sample 6 . The work to optimize the ratio of the adhesive and two diamond fractions in terms of the adhesive, strength, and heat-conducting properties will be continued.

The thermal resistances of samples 1-4 measured using a KPTD-2/1-0.20 thermal pad as a thermal interface were $1.9 \pm 0.97 ; 2.96 \pm 0.22 ; 2.94 \pm 0.54$; $2.27 \pm 0.49 \mathrm{~K} / \mathrm{W}$, respectively.

When measuring the thermal resistance of samples 5-7, we replaced the KPTD-2/1-0.20 thermal pad from NOMAKON with FGS graphene paper (see Fig. 4) to improve the accuracy of the results. Having a lower thermal resistance, the graphene paper provides more accurate measurements of the thermal resis tances in the range of less than $1 \mathrm{~K} / \mathrm{W}$. The measured values for samples 5-7 were $0.28 \pm 0.08,0.05 \pm 0.01$, and $1.58 \pm$ $0.46 \mathrm{~K} / \mathrm{W}$, respectively. The temperature dependence used for calculating the thermal resistance of sample 6 is shown in Fig. 5 as an illustration.

Let us look at the properties of the adhesives used between the aluminum fin and the FEB. The heaters were glued to the $7.2 \times 19 \mathrm{~mm}$ plate made of the same material as the fins using the adhesive that showed the lowest thermal resistance (sample 6), the TPK-21 film

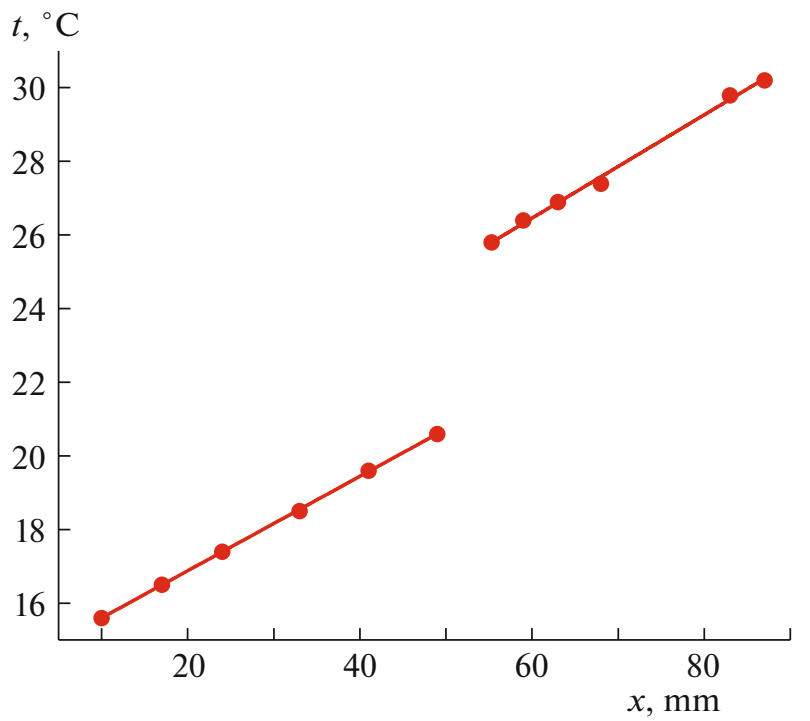

Fig. 5. The graph for determining the temperature gradient in sample 6.

adhesive, and 3M 9448A double-sided adhesive tape. The temperature was measured between the chips at a supplied power of $8.7 \mathrm{~W}$ (Table 2). The best heat dissipation was shown by a $110-\mu$ m-thick film adhesive with the addition of diamond powder.

\subsection{The Measurement \\ of the Temperature Gradient on the Fins}

The simulators of the FEBs were tested on a duralumin fin using the adhesive with the diamond powder that was applied between the FEB and the fin.

A $90 \times 40 \mathrm{~mm}$ FEB was attached to the cooling fin to which the simulators of STS-XYTER applicationspecific integrated circuit with a supplied power of $9.6 \mathrm{~W}$ and the simulators of the LDO voltage regulators with a supplied power of $3.2 \mathrm{~W}$ were glued. The fins were connected to the aluminum cooling plate, which in turn was connected to the water-cooled thermostat (LAUDA MC 250), allowing the coolant temperature

Table 2. The average temperature $t$ of the chips with different adhesives (the temperature of the aluminum plate was $\left.+20^{\circ} \mathrm{C}\right)$

\begin{tabular}{l|c}
\hline \multicolumn{1}{c|}{ Adhesives } & $t,{ }^{\circ} \mathrm{C}$ \\
\hline $\begin{array}{l}\text { Adhesive with the addition of diamond powder } \\
18: 1(100 \mu \mathrm{m})\end{array}$ & $28.1 \pm 1.3$ \\
Film adhesive $(100 \mu \mathrm{m})$ & $28.6 \pm 0.7$ \\
$\begin{array}{l}\text { Film adhesive with the addition of diamond } \\
\text { powder }(110 \mu \mathrm{m})\end{array}$ & $25.9 \pm 1.5$ \\
$\begin{array}{l}\text { Film adhesive with the addition of diamond } \\
\text { powder }(160 \mu \mathrm{m})\end{array}$ & $28.1 \pm 1.4$ \\
Heat-conductive tape $(500 \mu \mathrm{m})$ & $33.4 \pm 2.5$ \\
\hline
\end{tabular}




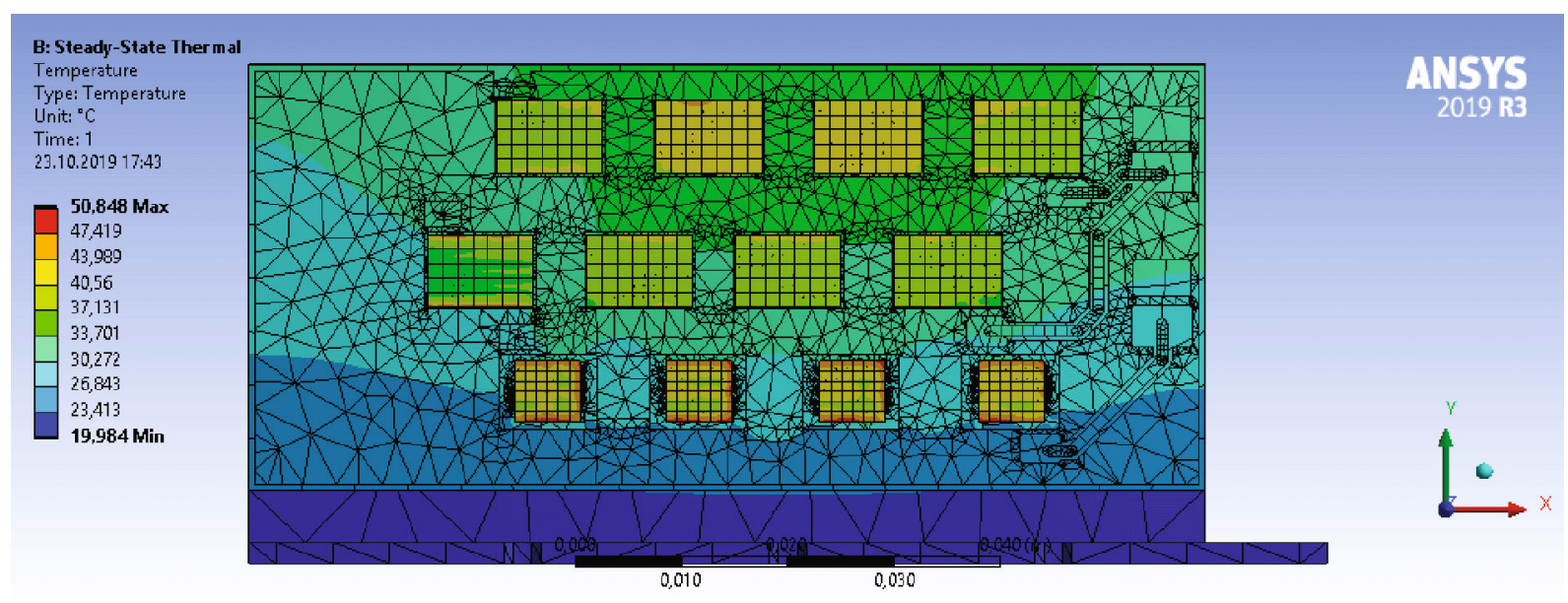

Fig. 6. The model of the cooling fin.

to be reduced to $5^{\circ} \mathrm{C}$. The thermocouples connected to a FLUKE+17B multimeter were used to measure the temperature. The thermal model was built using the ANSYS software package (Fig. 6). The measured and calculated temperatures are presented in Table 3. The average temperature of the integrated-circuit simulators was $\sim 41^{\circ} \mathrm{C}$, while the temperature of the base of the cooling fin was $\sim 20^{\circ} \mathrm{C}$. As can be seen from these data, the measured and calculated values coincided within the measurement accuracy.

To improve heat dissipation, through holes were drilled in the board under the chips and were filled with copper (the so-called Thermal vias system) [16], which contributed to additional heat dissipation through FR4 fiberglass to the external radiator.

The simulation showed that an increase in the fin thickness from 2 to $3 \mathrm{~mm}$ made it possible to reduce the temperature by $4^{\circ} \mathrm{C}$ and more. Fin thicknesses of 1.0 and $2.5 \mathrm{~mm}$ were additionally considered. The results are shown in Table 4.

We indicated in Subsection 2.1 that sample 6 made of carbon-fiber plastic had a higher thermal conductivity in the longitudinal direction $\left(\lambda_{\|}=254 \mathrm{~W} /(\mathrm{m} \cdot \mathrm{K})\right)$, but a lower thermal conductivity in the transverse

Table 3. The simulation results in comparison with the measurements of the chip temperatures at a cooling-thermostat temperature of $+5.5^{\circ} \mathrm{C}$ and a fin-base temperature of $+20^{\circ} \mathrm{C}$

\begin{tabular}{l|c|c}
\hline \multirow{2}{*}{$\begin{array}{c}\text { Point of temperature } \\
\text { measurement }\end{array}$} & \multicolumn{2}{|c}{ Temperature, ${ }^{\circ} \mathrm{C}$} \\
\cline { 2 - 3 } & $\begin{array}{c}\text { ANSYS } \\
\text { calculation }\end{array}$ & $\begin{array}{c}\text { measured } \\
\text { values }\end{array}$ \\
\hline Top row of chips & 42.3 & $42.4 \pm 2.4$ \\
Bottom row of chips & 39.7 & $40.6 \pm 4.8$ \\
Chips of the LDO voltage regulators & 42.4 & $43.1 \pm 7.3$ \\
\hline
\end{tabular}

direction $\left(\lambda_{\perp}=14 \pm 3.4 \mathrm{~W} /(\mathrm{m} \cdot \mathrm{K})\right)$ than the D16T duralumin. Simulations with six fins differing in their sizes were performed to clarify the thermal performance of the fins produced from advanced composite materials. To estimate the efficiency of heat removal, we performed the simulations of similar structures in which only the properties of the materials were changed.

The simulation results showed that the temperatures of the carbon-fiber plastic fin are lower by $4^{\circ} \mathrm{C}$ relative to the duralumin fin (Table 5). Such a gain in temperature does not justify the complexity of manufacturing a cooling fin from carbon-fiber reinforced plastic.

\subsection{Comparison of the Thermal Interfaces between an Aluminum Heat Sink and a Fin}

Unlike the thermal interface between the FEB and the fin, the thermal interface between an aluminum heat sink and a fin does not have to provide electrical insulation, since there is no electrical contact with the electronic components. The high thermal conductivity of the thermal interface and its chemical neutrality to aluminum alloys are important characteristics for the selection of the thermal interface.

A comparison of heat-conducting materials (FGS graphene paper moistened with glycerin, various types of thermal pastes and thermal pads) was made to select the thermal interface. The values of the temperature difference between the bases of the fin and the aluminum heat sink are presented in Table 6 . The heat was removed by cooling the thermostat with refrigerant from the K6 recirculating refrigerant (Applied Thermal Control).

The following thermal interfaces were tested:

(1) GD900 thermal paste, $4.5 \mathrm{~W} /(\mathrm{m} \cdot \mathrm{K})$;

(2) Polimetech PK-2 thermal paste, $10.2 \mathrm{~W} /(\mathrm{m} \cdot \mathrm{K})$; 
Table 4. The change in the temperature vs. the thickness of the aluminum fin at a fin-base temperature of $+20^{\circ} \mathrm{C}$

\begin{tabular}{c|c|c|c}
\hline \multirow{2}{*}{ Fin thickness, mm } & \multicolumn{3}{|c}{ Temperature, ${ }^{\circ} \mathrm{C}$} \\
\cline { 2 - 4 } & top row of chips & bottom row of chips & LDO voltage regulator \\
\hline 1.0 & 48.90 & 44.50 & 45.70 \\
2.0 & 43.90 & 41.88 & 42.55 \\
2.5 & 41.80 & 39.40 & 41.22 \\
3.0 & 37.97 & 35.66 & 31.97 \\
\hline
\end{tabular}

Table 5. The comparison of the heat dissipation on the cooling fins made of different materials at a fin-base temperature of $+20^{\circ} \mathrm{C}$

\begin{tabular}{l|c|c|c}
\hline \multirow{2}{*}{ Fin material } & \multicolumn{3}{c}{ Temperature, ${ }^{\circ} \mathrm{C}$} \\
\cline { 2 - 4 } & top row of chips & bottom row of chips & LDO voltage regulator \\
\hline Aluminum & 41.3 & 39.1 & 39.9 \\
Carbon-fiber reinforced plastic & 37.4 & 35 & 37.6 \\
\hline
\end{tabular}

(3) FGS graphene paper, $120 \mathrm{~W} /(\mathrm{m} \cdot \mathrm{K})$;

(4) KPTD 2/1-0.20 thermal pad, $1 \mathrm{~W} /(\mathrm{m} \cdot \mathrm{K})$;

(5) Thermalright TF8 thermal paste, $13.8 \mathrm{~W} /(\mathrm{m} \cdot \mathrm{K})$;

(6) Thermal Grizzly Carbonaut thermal pad, $62.5 \mathrm{~W} /(\mathrm{m} \cdot \mathrm{K})$;

(7) Thermalright TFX thermal paste, $14.3 \mathrm{~W} /(\mathrm{m} \cdot \mathrm{K})$.

From the data in Table 6, it can be seen that the use of a thermal paste, compared to thermal pad and FGS graphene paper, significantly reduced the temperature difference between the cooling plate and the base of the cooling fin.

\section{CONCLUSIONS}

The cooling system is an important part of the BM@N silicon tracking system. Calculations were performed using the ANSYS software package and the measurements were made with various materials of cooling fins and adhesives in order to select optimal materials and attain the minimum temperature gradient between the chips and the liquid coolant.
The simulations have shown that the use of carbonfiber reinforced plastic with a thickness of $2 \mathrm{~mm}$ or more improves heat dissipation only slightly compared to an aluminum plate with the same thickness. This can be attributed to the fact that the thermal conductivity of carbon-fiber reinforced plastic is significantly lower in the transverse direction than in the longitudinal direction. It seems that the difficulties in manufacturing a cooling fin from carbon-composite materials make its use in the silicon tracking system of the BM@N experiment unjustified, although it provides a small gain in the temperature compared to an aluminum fin.

Various types of adhesives have also been tested. The best results were shown by sample 6 with two different fractions of diamond powder in a ratio of $1: 18$. Similar values were obtained for the heat dissipation when comparing the best of the homemade liquid adhesives to TPK-21 film adhesive. The best characteristics were shown by a $110-\mu \mathrm{m}$-thick film adhesive loaded with the diamond powder. This adhesive was specially produced by OOO NPF Tekhpolikom (Mos-

Table 6. Testing of heat-conducting materials at a cooling-thermostat temperature of $+10^{\circ} \mathrm{C}$

\begin{tabular}{l|c|c|c}
\hline \multicolumn{1}{c|}{ Heat-conducting material } & \multicolumn{2}{|c|}{ Temperature, ${ }^{\circ} \mathrm{C}$} & \multirow{2}{*}{$\Delta T,{ }^{\circ} \mathrm{C}$} \\
\cline { 2 - 3 } & aluminum heat sink & fin base & \\
\hline 1. GD900 thermal paste, $4.5 \mathrm{~W} /(\mathrm{m} \cdot \mathrm{K})$ & 21.6 & 23.3 & 1.7 \\
2. Polimetech PK-2 thermal paste, $10.2 \mathrm{~W} /(\mathrm{m} \cdot \mathrm{K})$ & 17.96 & 19.3 & 1.3 \\
3. FGS graphene paper & 25.3 & 38.4 & 13.1 \\
4. KPTD 2/1-0.20 thermal pad, $1 \mathrm{~W} /(\mathrm{m} \cdot \mathrm{K})$ & 26.7 & 33.9 & 7.2 \\
5. Thermalright TF8 thermal paste, $13.8 \mathrm{~W} /(\mathrm{m} \cdot \mathrm{K})$ & 17.1 & 18.0 & 0.9 \\
6. Thermal Grizzly Carbonaut thermal pad, $62.5 \mathrm{~W} /(\mathrm{m} \cdot \mathrm{K})$ & 21.4 & 27.2 & 5.8 \\
7. Thermalright TFX thermal paste, $14.3 \mathrm{~W} /(\mathrm{m} \cdot \mathrm{K})$ & 26.1 & 26.8 & 0.7 \\
\hline
\end{tabular}


cow) using a technology similar to TPK-21. Work in this direction is expected to continue.

The thermal prototypes of the FEBs on an aluminum heat sink were tested. The temperature gradient between the chip and the cooling surface was $22^{\circ} \mathrm{C}$ at the cooling fin. It was also shown that an increase in the fin thickness makes it possible to reduce the temperature of the chips.

The comparison of the thermal interfaces between the aluminum heat sink and the cooling plate showed that the thermal paste provides better heat dissipation compared to FGS graphene paper and thermal pads.

\section{FUNDING}

The research was funded by RFBR according to the projects 18-02-40113 and 19-32-90001.

\section{REFERENCES}

1. Senger, P. and Dementev, D., Particles, 2019, vol. 2, p. 481.

https://doi.org/10.3390/particles2040029

2. CBM Collaboration, Silicon Tracking System (STS), Technical Design Report, GSI, 2012. http://repository.gsi.de/record/54798/files/GSI-Report-2013-4.pdf.

3. The Silicon Tracking System as Part of the Hybrid Tracker of the BM@N Experiment, Technical Design Report, Dubna, 2019. https://bmn-wiki.jinr.ru/bin/download/Doc/4. Documents/4.4 BM\%40N TDR/Hybrid tracker/WebHome/TDR_BM_N_hybrid_tracker_final.pdf?rev=1.2.

4. Aksöz, S., Ocak, Y., Maraslı, N., Cadirli, E., Kaya, H., and Böyük, U., Exp. Therm. Fluid Sci., 2010, vol. 34, p. 1507.

https://doi.org/10.1016/j.expthermflusci.2010.07.015
5. Tablitsy fizicheskikh velichin. Spravochnik (Tables of Physical Quantities. Handbook), Kikoin, I.K., Ed., Moscow: Atomizdat, 1976.

6. Ovchinnikov, I.I. and Ovchinnikov, I.G., Internet-Zh. Naukoved., 2012, no. 4, p. 98.

7. Grushko, O.E., Vse Mater. Entsikl. Sprav., 2007, no. 2, p. 13.

8. Zherebchevsky, V.I., Altsybeev, I.G., Feofilov, G.A., Igolkin, S.N., Krymov, E.B., Lazareva, T.V., Maltsev, N.A., Prokofiev, N.A., Nesterov, D.G., Francescon, A., Gargiulo, C., Laudi, E., and Marzoa, M.G., J. Instrum., 2018, vol. 13, no. 8, p. T08003.

https://doi.org/10.1088/1748-0221/13/08/T08003

9. Maier, S., MSc Thesis, Karlsruhe Institute of Technology, 2016. https://publish.etp.kit.edu/record/21348.

10. Zinchenko, V.F., Mekh. Polim., 1969, no. 3, p. 284.

11. Popov, V.M., Novikov, A.P., Kvitko, K.S., Kalashnikov, N.S., and Vnukov, A.N., Voronezh. NauchnoTekh. Vestn., 2018, no. 1 (23), p. 41. http://vestnikvglta.ru/arhiv/2018/1-1-23-2018/41-46.pdf.

12. Mozgovoi, N.V., Popov, V.M., and Popov, D.V., Vestn. Voronezh. Gos. Tech. Univ., 2018, vol. 14, no. 3, p. 56.

13. Teertstra, P., Proc. ASME InterPack Conference IPACK 2007, Vancouver, July 8-12, 2007. https://www.semanticscholar.org/paper/ThermalConductivity-andContact-Resistance-forTeertstra/cf6e0b53b934ac9236b7 adb226e54fce0c52f40d.

14. Zong, C., A Mathematical Theory for Random Solid Packings, 2014-10-04. http://arxiv.org/abs/1410.1102.

15. Dias, R.P., Teixeira, J.A., Mota, M.G., and Yelshin, A.I., Ind. Eng. Chem. Res., 2004, vol. 43, p. 7912. https://doi.org/10.1021/ie040048b

16. Vinokurov, A., Poluprovodn. Svetotekh., 2010, no. 3, p. 16.

Translated by N. Goryacheva 